\title{
Noninvasive Determination of Epidermal and Stratum Corneum Thickness in vivo Using Two-Photon Microscopy and Optical Coherence Tomography: Impact of Body Area, Age, and Gender
}

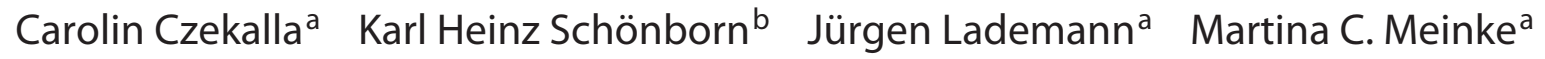 \\ a Department of Dermatology, Venerology and Allergology, Center of Experimental and Applied Cutaneous Physiology, \\ Charité - Universitätsmedizin Berlin, corporate member of Freie Universität Berlin, Humboldt-Universität zu Berlin, and \\ Berlin Institute of Health, Berlin, Germany; ${ }^{b}$ W.O.M. WORLD OF MEDICINE GmbH, Berlin, Germany
}

\begin{abstract}
Keywords
Two-photon microscopy - Optical coherence tomography . Epidermal thickness · Stratum corneum · Auto fluorescence . Second harmonic generation
\end{abstract}

\begin{abstract}
Background: High-resolution images of the epidermis are important to understand the transdermal penetration and changes in epidermal components. Both ex vivo and in vivo technologies are available to picture the epidermal thickness (ET). So far, the illustration of the stratum corneum (SC) has not been possible without artifacts. Objective: Precision in vivo measurement of the ET and SC, duly considering the impact of location on the body, age, and gender. Methods: In this pilot study on 20 skin-healthy subjects aged 18-66 years, the ET was imaged by two-photon microscopy (2PM) and optical coherence tomography (OCT), and the SC by using 2PM at five different body sites. Results: On solar-exposed body areas, both the epidermis and SC are thicker compared to solar-protected areas $(p<0.05)$, the epidermis
\end{abstract}

\section{KARGER}

() 2019 S. Karger AG, Basel

E-Mail karger@karger.com

www.karger.com/spp at the gluteal region being the thickest $(p<0.05)$. The ET decreases with age $(p<0.05)$. Males show a thicker epidermis than females $(p<0.05)$. Conclusion: 2PM provides a noninvasive method for imaging the epidermis and especially the $\mathrm{SC}$ in vivo and is optimally suited for the application of histological criteria.

(c) 2019 S. Karger AG, Basel

\section{Introduction}

The average thickness of the stratum corneum (SC) ranges from 10 to $30 \mu \mathrm{m}$ [1-3]. The SC, being the outermost cell layer, has direct contact to the environment and therefore a special role. It functions as a protective barrier against extrinsic influences such as ultraviolet (UV) radiation, dehydration, and penetration. In addition, it offers the opportunity to observe the occurrences of hyperkeratosis as well as the healing processes of wounds [3, 4]. Furthermore, the quantification of the epidermal thickness (ET) is of great importance, in order to be able
Prof. Dr. Martina C. Meinke

Klinik für Dermatologie, Venerologie und Allergologie

Charité - Universitätsmedizin Berlin

Charitéplatz 1, DE-10117 Berlin (Germany)

E-Mail martina.meinke@ charite.de 
to evaluate the influential factors upon the protective function of the skin $[5,6]$.

Prior studies have established various algorithms to measure the epidermal layer thickness but are very difficult to compare [6-8]. The epidermis can be depicted ex vivo and in vivo. Still the gold standard in skin diagnosis is histology. A general disadvantage of histology is the need to excise tissue samples, i.e., being primarily invasive. Several noninvasive, image-producing methods like laser scanning microscopy (LSM), confocal Raman spectroscopy (CRS), multiphoton microscopy (MPM), and optical coherence tomography (OCT) provide alternative options to depict the different skin layers [2, 5, 8-16]. They must be able to depict the epidermal layers and their components at high resolution. LSM and CRS produce horizontal images in multiple stacks, whereas OCT generates vertical images of a cross section of both the epidermis and dermis. Thus, the latter method may establish a direct comparison to the histological findings in order to evaluate the ET and morphological structures $[6,12,14,17,18]$.

Two-photon microscopy (2PM) is a new, noninvasive optical method, also permitting vertical scans [19]. OCT can be employed as a comparative reference to $2 \mathrm{PM}$ and can verify the quality and applicability of $2 \mathrm{PM}[4,19]$. The depiction of the SC and the exact determination of its thickness has not been possible up to now, either invasively or noninvasively [3, 17]. Quantification by OCT may be possible only at the palm and plantar and with hyperkeratotic skin $(S C>50 \mu \mathrm{m})[4,6]$. Keeping in mind the incorrect depiction of the SC, OCT measurements of the ET reported so far seem to be approximate.

The purpose of this study was to depict the SC and the entire epidermis in detail and to determine their thicknesses with high accuracy. Within this framework, the influence of intrinsic factors such as, age, gender, and body region upon the thickness of the epidermis and its layer were to be shown and evaluated. The results of the measurements of the ET by means of the 2PM and OCT were to be compared, in order to prove the applicability of the $2 \mathrm{PM}$ in the field of dermatology more clearly.

\section{Materials and Methods}

\section{Subjects}

This pilot study included 20 subjects from Germany, who were free of barrier disruption or skin diseases. The participants consisted of 10 men and 10 women of skin type II [20]. All subjects were over 18 years of age and divided into three age groups: $18-30$ years $(n=7), 31-50$ years $(n=7)$, and $50-66$ years $(n=6)$. They had a body mass index between 19.5 and 26.3 , expressed in units $\mathrm{kg} / \mathrm{m}^{2}$ resulting from mass in kilograms and height in meters. The criteria for inclusion and exclusion were accorded and approved by the ethics committee of Berlin (DIMDI No. 00008670 (A), EUDAMED No. CIV-13-08-0115553). The procedure was in agreement with the guidelines of the Declaration of Helsinki. Excluded were pregnant and breast-feeding women, subjects who were placed in an institution enacted by judicial and governmental order (according to $\$ 29$ German Medical Devices Act), and persons with known or continuing abuse of drugs or alcohol. All subjects gave their written consent prior to beginning the study [21].

\section{Two-Photon Microscopy}

The innovative 2PM (2PM VertiSCAN V.21; W.O.M. WORLD OF MEDICINE GmbH, Berlin), which was used for this study, employs a "flying optic" to generate a scan of the skin. The laser focus moves laterally through the adjusted skin area with a high scan speed (up to $40 \mathrm{~mm} / \mathrm{s}$ ), together with an ultra-light (14 g) scan lens with a wide aperture $(\mathrm{AN}=1.25)$. A false color image with a pixel resolution of $0.5-50 \mu \mathrm{m}$ is generated [19]. Collagen structures yield a separate specific signal by the nonlinear process of second harmonic generation (SHG). The autofluorescent (AF) and SHG images are generated simultaneously after an excitation at $780 \mathrm{~nm}$ with a size of $7 \mathrm{~mm}$ in the $x$ direction (lateral) and $500 \mu \mathrm{m}$ in the $z$ direction (vertical). Collected response signals were detected with a range of 380-410 $\mathrm{nm}$ (channel 1) being the SHG signal and a range of $415-720 \mathrm{~nm}$ (channel 2) being identified as the AF signal $[21,22]$.

\section{Optical Coherence Tomography}

A VivoSight Scanner "VivoSight 3.2" (Michaelson, Kent, Great Britain) was used in this study. This multi-beam system with a "swept source frequency domain" (A-line rate $20 \mathrm{kHz}$ ) is connected to a high-speed laser scanner ( $\operatorname{santec}^{\circledR}$, Japan). The tissue is imaged in a scan region of $6 \times 6 \mathrm{~mm}$ at a depth of $1-2 \mathrm{~mm}$, depending on the opaque material, below the skin surface at an optical resolution (in the tissue) of $<7.5 \mu \mathrm{m}$ lateral and $<5 \mu \mathrm{m}$ axial. A focus depth of $1.0 \mathrm{~mm}$ can be achieved [23-25]. The VivoSight uses a central wavelength of $1,305 \mathrm{~nm}$. Tissue components are visualized by their different scattering coefficients based on the respective refraction index of the cellular components for the investigation the vertical A-scan was used.

\section{Procedure}

The thickness of both the epidermis and the SC was investigated at five body sites of each subject, only on healthy skin. The body sites were selected as they represented a variety of diversely structured skin areas with differing sun exposure. The volar (ventral, flexor) forearm in extension position, abdomen (region above the hip bone), gluteal (crista iliaca, transition of back to buttocks), and sural (calf, centric) regions are deemed to be solar protected, whereas the dorsal (outer, extensor) forearm belongs to a rather sun-exposed region $[25,26]$. Each skin area of these five body sites was scanned with the $2 \mathrm{PM}$ using a subject preparation and scanning technique, which had been optimized in a former study [19]. The test persons were lying on top of a cosmetic couch (Kosmetikliege Queen I Classic 1-motoring; Soleni Classic), which was used in order to ensure that the body sites to be investigated could be positioned as accurately as possible. Every skin area was shaved (Wilkinson Sword, nonsterile, Art.-Nr. 182H; Wilkinson Sword $\mathrm{GmbH}$, Solingen, Germany), disinfected three times (Softasept ${ }^{\circledR} \mathrm{N}$ 


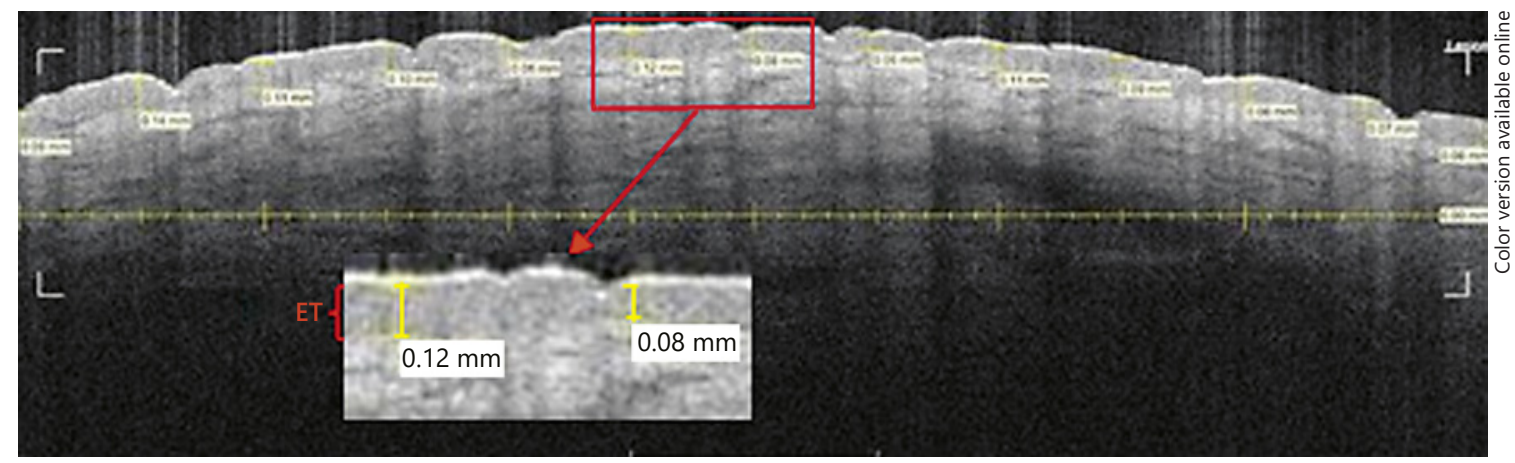

Fig. 1. An OCT scan of the skin in the abdominal region of a 23-year-old man (age group 1). The epidermal thickness (ET) was detected on the basis of the clear contrast of the different gray levels. The ET was scaled every $0.5 \mathrm{~mm}$ vertically at an angle of $90^{\circ}$.
That means 13 values produce a mean ET per picture or rather body area. The stratum corneum is not visible. The outermost white signal is an artifact. Image 38 out of $60.6 \times 2 \mathrm{~mm}$.
Braun, Art-Nr. 3887138, Hamburg, Germany), and finally water was applied as the contact medium and for index match. On the basis of an overview scan ( $x z$ axes: $2,000 \times 4,000 \mu \mathrm{m}^{2}$, image resolution: $10 \mu \mathrm{m}$, speed: $\left.10 \mathrm{mms}^{-1}\right)$ a detailed scan at a resolution of $1 \mu \mathrm{m}$ (= 1 pixel) was programmed. The image display was followed by the image processing program DataViewer Version 1.3, whereas channel 1 (SHG) and 2 (AF) were used $[19,21,27]$.

The SC thickness was calculated as the distance between the first superficial structures to the beginning of the stratum granulosum $[1,2]$. ImageJ was used to measure the thickness of the SC every 125 pixels at a false color image.

The ET was calculated for the 2PM scan by using the DataViewer. Therefore, the image data was accessed in the single channel category. The layer thickness was noted every $150 \mu \mathrm{m}$ by the adjustment of a curser at the particular channel in counts/pixel. The ET was defined as the vertical distance between the uppermost imaged skin site and the dermo-epidermal junction zone, i.e., from the onset of the AF signal until the SHG signal starts $(Z=$ vertical scale in the tissue, in $\mu \mathrm{m})$ :

$$
E T=Z(\text { onset of } S H G \text { signal })-Z(\text { onset of AF signal }) .
$$

The minimum and maximum of the ET are characterized by the wave-like hills and valleys of the uppermost dermal papillae and epidermal rete ridge $[9,28]$.

Afterwards, the same body sites were visualized two times using the clinical OCT VivoSight. Scan A was used to get 60 frames of the entire image field. One of the recorded images was selected, which was free of hair follicles and disturbing artifacts. The epidermis is the less reflective band of frequency between the outmost bright reflection and the light backscattering layer, which is the dermis [12]. The approach of the measurement process of the ET is demonstrated in Figure 1.

\section{Statistics}

The program SPSS $22\left(\right.$ IBM $^{\circledR}$ SPSS $^{\circledR}$ Statistics) and Excel for Windows 10 was used for the statistical analysis. The data was analyzed by means of the nonparametric Kruskal-Wallis test, the unpaired $\chi^{2}$ and Mann-Whitney tests, as well as the paired Wilcoxon test. All $p$ values $<0.05$ were defined as statistically significant.

\section{Results}

Both the ET and SC were imaged by 2PM and OCT. The epidermis and upper dermis are shown in Figure 1 by OCT and in Figure 2 by 2PM. Figure 2 shows the entire epidermis including the SC. The SC is visible as the intensive autofluorescing uppermost layer (bright line). The less intense AF signal of the living epidermal cells is visible underneath. The waves of the dermo-epidermal junction zone are clearly visible in Figure 2. In Figure 1, the transition from the epidermis to the dermis appears more like an even line.

\section{Thickness of the SC Measured by 2PM}

The thickness of the SC increases from the sural region $>$ dorsal forearm $>$ volar forearm $>$ gluteal region $>$ abdomen. The SC thicknesses of all areas are shown in Figure 3. The SC thickness decreases significantly with age at the abdomen $(p=0.009)$, particularly from age groups 1 to $2(p=0.004)$ and age groups 1 to $3(p=0.032)$, as opposed to the gluteal region, where the SC thickness increases with age significantly $(p=0.015)$, especially from age groups 1 to $2(p<0.006)$ and age groups 1 to 3 $(p=0.032)$. There is no significant influence of gender on SC thickness to be observed.

\section{ET Measured by 2PM and OCT}

Using 2PM, all scanned body areas show different ETs. A decrease of the ET from the gluteal region $>$ dorsal forearm $>$ sural region $>$ volar forearm $>$ abdomen can be identified, which is pictured in the boxplot in Figure 4.

The ET at the gluteal region is significantly the thickest compared to all other skin sites $(p<0.05)$, independent of 


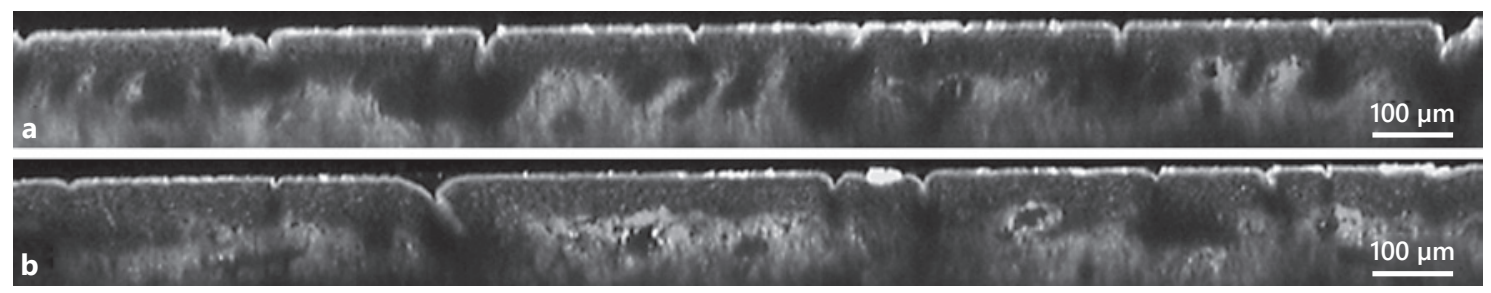

Fig. 2. A $2 \mathrm{PM}$ grey scale image of the skin area above the abdomen on a 23-year-old man (a) (mean epidermal thickness $[\mathrm{ET}]=83.51 \mu \mathrm{m}$, mean stratum corneum $[\mathrm{SC}]=14.86 \mu \mathrm{m} ; 1,895$ $\times 180 \mu \mathrm{m})$ and on a 57 -year-old man $(\mathbf{b})($ mean $\mathrm{ET}=69.22 \mu \mathrm{m}$, mean $\mathrm{SC}=11.31 \mu \mathrm{m} ; 1,900 \times 171 \mu \mathrm{m})$. The range of only the autofluorescent (AF) signal is the layer of epidermis. The first bright autofluorescent (AF) signal (thin line) shows the SC. The epidermis (dark grey) extends to the beginning of the second harmonic generation (SHG) signal (light grey), which detects the collagen fibers of the dermis. The grey scale of the dermis changes depending on the composition of collagen (SHG) and elastin fibers (AF) of the elastin net. The thickness of the SC decreases with age. Also visible are the furrows, which give the surface skin its characteristic form. With increasing age, a flattening of the epidermis is visible; the epidermal rete ridge (valleys) and dermal papillae (hills) are reduced.

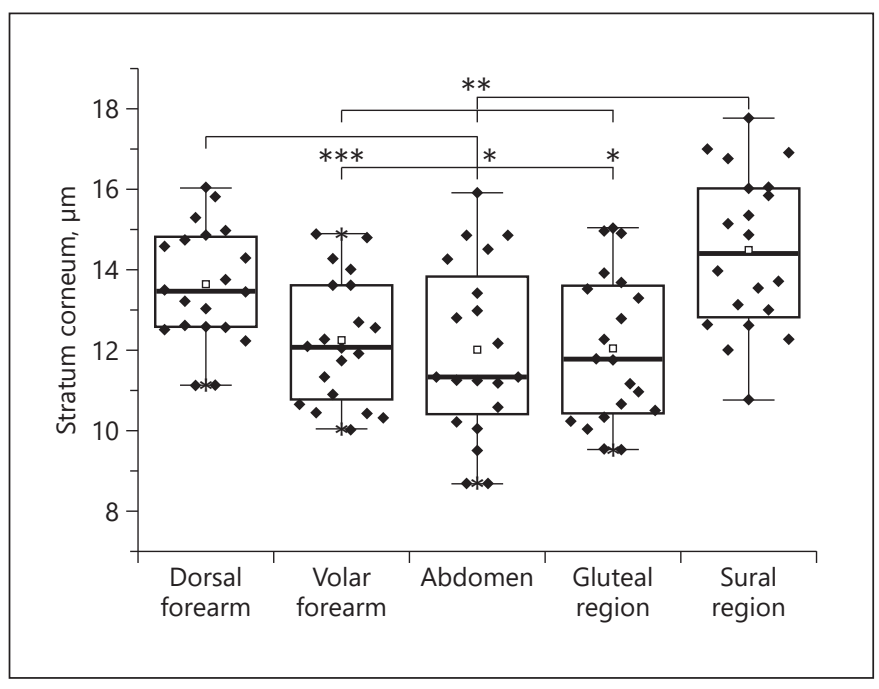

Fig. 3. A comparison of the values of the stratum corneum (SC) obtained by $2 \mathrm{PM}$ at different body areas. The significances were tested by the Wilcoxon test and are marked with ${ }^{*} p<0.05$, ${ }^{* *} p<$ 0.01 and ${ }^{* * *} p>0.001$. The SC at the dorsal forearm is significantly thicker than at the volar forearm $(p<0.001)$, gluteal region $(p=$ $0.017)$, and abdomen $(p=0.012)$. The SC at the sural region is significantly the thickest compared to all other body sites (volar fore$\operatorname{arm} p=0.001$, abdomen $p=0.001$, gluteal region $p=0.004)$, with the exception of the dorsal forearm.

both gender and age. The epidermis at the dorsal forearm is significantly thicker than at the volar forearm $(p=0.004)$ and abdomen $(p<0.001)$. The ET at the sural region is significantly thicker at the region of the abdomen $(p=0.001)$. The ET at the volar forearm is significantly thicker than at the abdomen $(p=0.003)$. The ET at the abdomen is the thinnest $(p<0.01)$.

In vivo Epidermal and Stratum Corneum Thickness Using 2PM

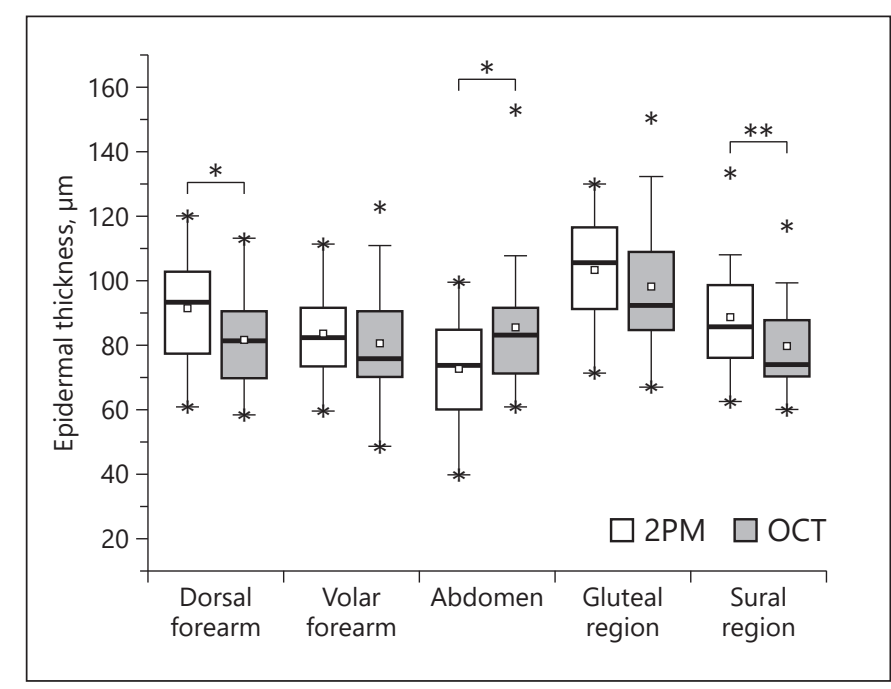

Fig. 4. Boxplot of the epidermal thickness of different body areas was calculated by the Wilcoxon test. Comparison of the epidermal values measured with two-photon microscopy (2PM) and optical coherence tomography (OCT). Statistically significant values are shown as $* p<0.05$ and ${ }^{* *} p<0.01$.

The impact of age on the ET is accompanied by a decreasing thickness corresponding to an increasing age. The epidermis at the dorsal forearm $(p=0.002)$ and volar forearm $(p=0.009)$ decreases significantly with age. The thinning of the epidermis at the dorsal forearm $(p=0.003)$, volar forearm $(p=0.01)$, and abdomen $(p=0.046)$ is significant between age groups 1 and 3 . The age-specific 
Fig. 5. Correlation analysis comparing the imaging processes $2 \mathrm{PM}$ and OCT by determination of the epidermal thickness at various skin areas (mean \pm SD; 2PM: $87.47 \pm$ $17.44 \mu \mathrm{m}$ vs. OCT: $83.14 \pm 16.25 \mu \mathrm{m}$ ). After the outlier test, the correlation index according to Pearson was calculated, excluding easy outliers. The correlation index was highly significant $(\mathrm{r}=0.494 ; p<0.0001$; $n=97)$.

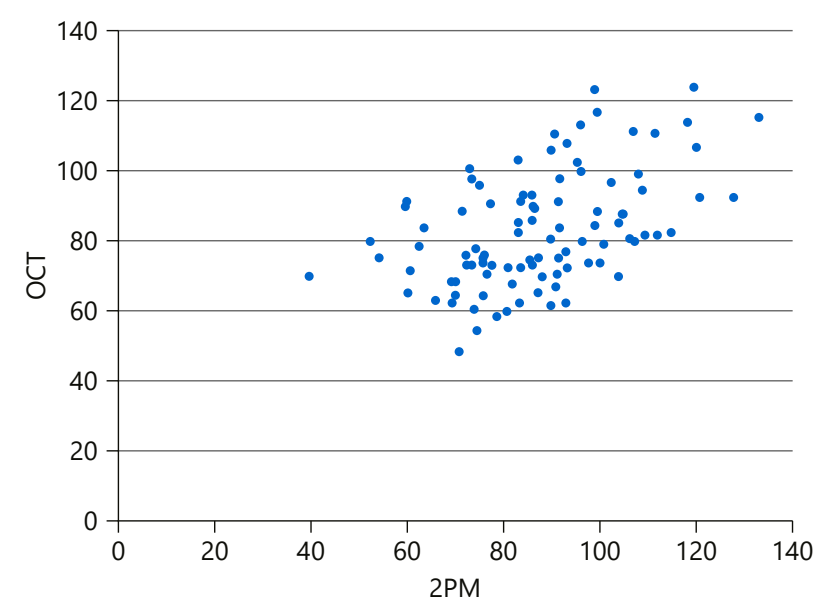

\section{Discussion}

Evaluation of the Thickness of the SC

The average SC thickness is, as measured noninvasively with the $2 \mathrm{PM}, 12.06 \mu \mathrm{m}$. Table 1 summarizes the heretofore published values of the SC thickness, which vary greatly in comparison to the values established by this study with respect to each body region.

Comparing the values of the SC thickness of all skin areas ascertained by this pilot study, it is obvious that the SC of the calf is the thickest. Of course, the SC of the calf and of the dorsal forearm is significantly thicker than that of the volar forearm, abdomen, and back. The thickness of the SC of the calf region could be due to less exfoliation contrary to other body sites [17]. A thicker SC on the dorsal forearm, as a UV-expressed skin area compared to nonchronically sun-exposed skin areas - such as the abdomen, volar forearm, and the back - goes hand in hand with the results found by Huzaira et al. [29], who detected, by means of CRS, a thinner and rougher SC in sun-protected skin areas compared to skin areas exposed to the sun. Already in 1997, Lock-Andersen et al. [30] pointed out that the SC showed a lesser photoprotection on body areas with less UV-expressed skin than on those with greater UV expression.

We could identify a change in the SC among participants of various ages. This change, however, could not be generalized for all skin locations. On the abdomen, the SC experiences significant thinning with age, whereas the opposite happens with age in the gluteal region where it thickens significantly. Various earlier studies resulted in similar controversial findings. OCT measurements have shown a 
Table 1. Comparison of stratum corneum (SC) thickness measured with different technologies, i.e., optical coherence tomography (OCT), confocal Raman spectroscopy (CRS), laser scanning microscopy (LSM), histology (Histo), and two-photon microscopy (2PM)

\begin{tabular}{|c|c|c|c|}
\hline Body area & Methods & $\mathrm{SC}, \mu \mathrm{m}$ & Reference \\
\hline Dorsal forearm & $\begin{array}{l}\text { OCT } \\
\text { CRS } \\
2 \mathrm{PM}\end{array}$ & $\begin{array}{l}13.49 \pm 2.05^{* *} \\
12.96 \pm 2.3^{* *} \\
\mathbf{1 3 . 6 1} \pm \mathbf{1 . 4 3 ^ { * * }}\end{array}$ & $\begin{array}{l}16 \\
29\end{array}$ \\
\hline Volar forearm & $\begin{array}{l}\text { OCT } \\
\text { CRS } \\
\text { LSM } \\
2 \mathrm{PM}\end{array}$ & $\begin{array}{c}10.4 \pm 0.9^{* *} \\
12.98 \pm 1.89^{* *} \\
18 \pm 3.9^{* *} \\
9.58 \pm 0.8^{* *} \\
16-22^{*} \\
12.22 \pm 1.55^{* *}\end{array}$ & $\begin{array}{l}1 \\
16 \\
1 \\
29 \\
2\end{array}$ \\
\hline Abdomen & $\begin{array}{l}\text { OCT } \\
2 \mathrm{PM}\end{array}$ & $\begin{array}{l}14.52 \pm 1.44^{* *} \\
11.99 \pm 2.13^{* *}\end{array}$ & 16 \\
\hline Back/gluteal region & $\begin{array}{l}\text { Histo } \\
\text { OCT } \\
\text { CRS } \\
\text { 2PM }\end{array}$ & $\begin{array}{c}14.9 \pm 3.4^{* *} \\
12 \pm 4^{* *} \\
14.56 \pm 2.38^{* *} \\
14.39 \pm 1.62 \\
10.41 \pm 0.8^{* *} \\
12.04 \pm 1.86^{* *}\end{array}$ & $\begin{array}{l}14 \\
37 \\
37 \\
16 \\
29\end{array}$ \\
\hline Leg/sural region & $\begin{array}{l}\text { OCT } \\
\text { CRS } \\
2 \mathrm{PM}\end{array}$ & $\begin{array}{r}13.7 \pm 1.4^{* *} \\
8.08 \pm 1.8^{* *} \\
22 \pm 6.9^{* *} \\
\mathbf{1 4 . 4 6} \pm \mathbf{1 . 9} \mathbf{9}^{* *}\end{array}$ & $\begin{array}{l}1 \\
29 \\
1\end{array}$ \\
\hline
\end{tabular}

The values written in bold are from this pilot study. The SC values are specified as mean value $\left(^{*}\right)$ or mean value \pm standard deviation $(* *)$. thickening of the SC with increasing age (abdomen) as well as a thinning (dorsal forearm and gluteal region) [16]. Other studies, however, were unable to identify any significant correlation of change in thickness of the SC as the skin aging experiments were performed using either a light microscope (ex vivo) or CRS (in vivo) [14-16, 30].

In this pilot study, no correlation of SC thickness and gender was apparent. Aside from Fruhstorfer et al. [31], who found a thinner SC on the volar fingertip of women compared to that of men, there are no earlier studies that identify any influence of gender on the thickness of the SC $[30,31]$.

\section{Comparison of the ET by Means of 2PM and OCT}

This study was able to show that, aside from the already known OCT method, $2 \mathrm{PM}$ provides a noninvasive imaging alternative to depict the epidermis in vivo.

In vivo Epidermal and Stratum Corneum Thickness Using 2PM
Table 2. Body area as impact of the epidermal thickness (ET): comparison of the ET of different body areas measured with different technologies such as optical coherence tomography (OCT), histology (Histo) and two-photon microscopy (2PM)

\begin{tabular}{|c|c|c|c|}
\hline Body area & Methods & $\mathrm{ET}, \mu \mathrm{m}$ & Reference \\
\hline Forearm & $\begin{array}{l}\text { Histo } \\
\text { OCT }\end{array}$ & $\begin{array}{c}60.9 \pm 20.0 \\
67.6 \pm 4.1 \\
102 \pm 7.4\end{array}$ & $\begin{array}{l}35 \\
38 \\
10\end{array}$ \\
\hline Dorsal forearm & $\begin{array}{l}\text { OCT } \\
\text { 2PM }\end{array}$ & $\begin{array}{c}85.96 \pm 7.98 \\
68.91 \pm 10.28 \\
\mathbf{8 2 . 3 5} \pm \mathbf{1 4 . 7 4} \\
\mathbf{1 0 4 . 9 3} \pm \mathbf{1 6 . 0 0}\end{array}$ & $\begin{array}{l}12 \\
16\end{array}$ \\
\hline Volar forearm & $2 \mathrm{PM}$ & $\begin{array}{c}88.2 \pm 11.9 \\
87.79 \pm 7.34 \\
66.36 \pm 7.36 \\
108 \pm 14 \\
104 \pm 24 \\
\mathbf{8 2 . 7 3} \pm \mathbf{1 7 . 6 9} \\
\mathbf{9 5 . 6 9} \pm \mathbf{1 2 . 6 1}\end{array}$ & $\begin{array}{l}8 \\
12 \\
16 \\
11 \\
39\end{array}$ \\
\hline Abdomen & $\begin{array}{l}\text { OCT } \\
2 \mathrm{PM}\end{array}$ & $\begin{array}{l}61.48 \pm 13.20 \\
\mathbf{8 4 . 1 5} \pm 22.04 \\
\mathbf{7 2 . 5 5} \pm \mathbf{1 5 . 9 1}\end{array}$ & 16 \\
\hline $\begin{array}{l}\text { (Upper) back/ } \\
\text { gluteal region }\end{array}$ & $\begin{array}{l}\text { Histo } \\
\text { OCT }\end{array}$ & $\begin{array}{c}81 \pm 13.5 \\
79.4 \pm 21.9 \\
106 \pm 15.4 \\
89.9 \pm 11.2 \\
66.33 \pm 16.72 \\
\mathbf{9 7 . 8 5} \pm \mathbf{2 3 . 8 3} \\
\mathbf{1 0 3 . 2 1} \pm \mathbf{1 5 . 7 8}\end{array}$ & $\begin{array}{l}14 \\
5 \\
5 \\
10 \\
16\end{array}$ \\
\hline $\begin{array}{l}\text { Lower leg/sural } \\
\text { region }\end{array}$ & $\begin{array}{l}\text { Histo } \\
\text { OCT }\end{array}$ & $\begin{array}{c}74.9 \pm 14.5 \\
85.87 \pm 67.58 \\
94.1 \pm 15.3 \\
\mathbf{7 9 . 4 6} \pm \mathbf{1 6 . 7 0} \\
\mathbf{1 0 2 . 9 1} \pm \mathbf{1 6 . 6 8}\end{array}$ & $\begin{array}{l}35 \\
10 \\
12\end{array}$ \\
\hline
\end{tabular}

The ET values are specified as mean value \pm standard deviation. The values written in bold are from this pilot study.

The higher resolution of the $2 \mathrm{PM}$ offers leads to the presumption that the so deducted values of the SC as well as the epidermal thicknesses are more exact than those by the OCT. Nevertheless, the boundary between the stratum papillare and the stratum reticulare is problematic and primarily the cause for inaccuracy $[9,10]$. Relatively constant references for the ET are given in the literature $[14,32]$. An overview of the values measured on the respective body areas for the ET both in the literature and the current pilot study is presented in Table 2 .

The 2PM and OCT measurements show that the gluteal region is the thickest compared to all other skin re- 
gions. The gluteal region is a good example of a skin location exposed to high mechanical stress. With greater strain on the skin, the elastic characteristics of the tissue increase [17].

Furthermore, this pilot study shows that the ET of the dorsal forearm is thicker compared to the ET of the volar forearm, the sural region, and the abdomen. This makes it possible to show an extrinsic influence on the skin such as UV radiation [33, 34]. UVA induces epidermal pigmentation [33]. The ET is thicker in sun-expressed skin areas than on those that are sun-protected. Because the ET of the back is thicker than that of the dorsal forearm, it stands to reason that the varying extrinsic factors influence and irritate the growth and differentiation processes in different amounts.

By contrast, the significant intrinsic influence of the body region on the thickness in one OCT study by Mogensen et al. could not be proven. In this study, there was no significant difference of the ET in relation to the dorsal and volar forearm and the sural region [12].

\section{The Effect of Age and Gender on the ET}

It has been shown through various imaging processes (light microscopy, OCT, LSM, CSR) that the thickness of the cellular epidermis decreases with redundant age $[6,12$, $13,15,30,35]$. The hypothesis of the epidermis thinning in advancing age could be demonstrably supported with the $2 \mathrm{PM}$, and previous results of other OCT studies could also be confirmed by use of the VivoSight. In our data analysis, the $2 \mathrm{PM}$ images showed a significant thinning of the ET with increasing age on the volar and dorsal forearm, with the OCT on the dorsal and volar forearm, the sural region, and abdomen. Both processes indicated a correlation between all five body regions in relation to age.

To that effect, Mogensen et al. proved on different anatomical skin areas (face, chest, neck, calf) by means of OCT that there was a statistically negative correlation between age and ET [12]. Controversially, the results of the study by Sandby-Moller et al. found no significant correlation between the ET of various skin areas (shoulder, dorsal forearm, buttocks) and age [14].

One must take into consideration that aside from intrinsic skin aging, there are extrinsic skin aging processes such as photoaging. Both effects are overlapping and act upon the various skin layers such as the epidermis and the dermis [36]. Exposure to the sun induces skin aging processes, which is reflected in swelling of the skin as well as a flattening of the dermo-epidermal junction zone, as shown in Figure 2 [13, 15, 21, 33, 36]. The interaction of both processes could be depicted by Neerken et al. [13] employing OCT and CRS. The thinning of the ET with age is different depending on the specific body sites. This effect is stronger on sun-protected skin than on unprotected skin. The thickness of the entire epidermis, as measured on the forearm, regresses significantly up to $15 \mu \mathrm{m}$ with increasing age.

Both the results of the $2 \mathrm{PM}$ and OCT showed gender-specific variance of ET. The results from the 2PM showing a thicker ET of men over and against the ET of women was significant in the abdomen and the sural region, and by means of OCT in the gluteal region. The OCT study of Mogensen et al. [12] did not reveal any gender-specific differences between the ET on 12 different anatomical regions. The study of Gambichler et al. [9] produced similar results. The influence of gender on the ET in the aging process could only be significantly determined on the forehead. As the ET reduces during the aging process in both nonchronic, sun-expressed skin areas as well as areas constantly in the sun, Gambichler et al. [9] conclude that UV radiation can only have a minor effect on the ET in the skin aging process.

\section{Conclusion}

The results showed that both methods, $2 \mathrm{PM}$ and OCT, are suited to identifying the ET and thus to evaluating intra-individual, intrinsic and extrinsic factors. The significant influence of age, gender, and body region on the epidermis should be taken into consideration when designing new studies and recruiting volunteers. Compared to the OCT, the new, innovative 2PM, with its higher resolution, offers a method for more accurate investigation of the ET with a more detailed depiction (e.g., of the rete ridge). In addition, 2PM allows for the imaging of the SC without artifacts. Because of this capability, this study was able to image and measure the SC vertically at various skin locations in vivo for the very first time over a length of a number of centimeters. It will be possible in the future to detect minimal effects and changes in the outer layers of the epidermis. For this reason, $2 \mathrm{PM}$ can be used to evaluate the effects of cosmetics, medicines, and environmental factors on the SC as well as on the cellular epidermis.

\section{Acknowledgments}

We would like to thank WORLD OF MEDICINE GmbH for providing the 2PM measurement device and the Foundation of Skin Physiology for financial support. 


\section{Statement of Ethics}

The study was approved by the Federal Institute for Drugs and medical Devices and the regional ethics committee of Berlin (DIMDI No. 00008670 (A) and EUDAMED No. CIV-13-08011553). All patients provided written informed consent. The study was conducted according to the guidelines of Good Clinical Practice.

\section{Disclosure Statement}

The authors have no conflict of interest to declare.

\section{References}

1 Crowther JM, Sieg A, Blenkiron P, Marcott C, Matts PJ, Kaczvinsky JR, et al. Measuring the effects of topical moisturizers on changes in stratum corneum thickness, water gradients and hydration in vivo. Br J Dermatol. 2008 Sep;159(3):567-77.

2 Lademann J, Richter H, Astner S, Patzelt A, Knorr F, Sterry W, et al. Determination of the thickness and structure of the skin barrier byin vivolaser scanning microscopy. Laser Phys Lett. 2008;5(4):311-5.

3 Richter T, Peuckert C, Sattler M, Koenig K, Riemann I, Hintze U, et al. Dead but highly dynamic-the stratum corneum is divided into three hydration zones. Skin Pharmacol Physiol. 2004 Sep-Oct;17(5):246-57.

4 Lademann J, Otberg N, Richter H, Meyer L, Audring H, Teichmann A, et al. Application of optical non-invasive methods in skin physiology: a comparison of laser scanning microscopy and optical coherent tomography with histological analysis. Skin Res Technol. 2007 May;13(2):119-32.

5 Gambichler T, Boms S, Stücker M, Kreuter A, Moussa G, Sand M, et al. Epidermal thickness assessed by optical coherence tomography and routine histology: preliminary results of method comparison. J Eur Acad Dermatol Venereol. 2006 Aug;20(7): 791-5.

6 Gambichler T, Boms S, Stücker M, Kreuter A, Sand M, Moussa G, et al. Comparison of histometric data obtained by optical coherence tomography and routine histology. J Biomed Opt. 2005 Jul-Aug;10(4):44008.

7 Toki F, Honkura N, Shirakata Y, Imamura T, Higashiyama S, Nanba D. Second harmonic generation reveals collagen fibril remodeling in fibroblast-populated collagen gels. Cell Struct Funct. 2013;38(2):227-36.

8 Weissman J, Hancewicz T, Kaplan P. Optical coherence tomography of skin for measurement of epidermal thickness by shapeletbased image analysis. Opt Express. 2004 Nov; 12(23):5760-9.

9 Gambichler T, Matip R, Moussa G, Altmeyer $\mathrm{P}$, Hoffmann K. In vivo data of epidermal thickness evaluated by optical coherence tomography: effects of age, gender, skin type, and anatomic site. J Dermatol Sci. 2006 Dec; 44(3):145-52.
10 Josse G, George J, Black D. Automatic measurement of epidermal thickness from optical coherence tomography images using a new algorithm. Skin Res Technol. 2011 Aug;17(3):314-9.

11 Maiti R, Gerhardt LC, Lee ZS, Byers RA, Woods D, Sanz-Herrera JA, et al. In vivo measurement of skin surface strain and sub-surface layer deformation induced by natural tissue stretching. J Mech Behav Biomed Mater. 2016 Sep;62:556-69.

12 Mogensen M, Morsy HA, Thrane L, Jemec GB. Morphology and epidermal thickness of normal skin imaged by optical coherence tomography. Dermatology. 2008;217(1):14-20.

13 Neerken S, Lucassen GW, Bisschop MA, Lenderink E, Nuijs TA. Characterization of agerelated effects in human skin: A comparative study that applies confocal laser scanning microscopy and optical coherence tomography. J Biomed Opt. 2004 Mar-Apr;9(2):274-81.

14 Sandby-Møller J, Poulsen T, Wulf HC. Epidermal thickness at different body sites: relationship to age, gender, pigmentation, blood content, skin type and smoking habits. Acta Derm Venereol. 2003;83(6):410-3.

15 Sauermann K, Clemann S, Jaspers S, Gambichler T, Altmeyer P, Hoffmann K, et al. Age related changes of human skin investigated with histometric measurements by confocal laser scanning microscopy in vivo. Skin Res Technol. 2002 Feb;8(1):52-6.

16 Tsugita T, Nishijima T, Kitahara T, Takema Y. Positional differences and aging changes in Japanese woman epidermal thickness and corneous thickness determined by OCT (optical coherence tomography). Skin Res Technol. 2013 Aug; 19(3):242-50.

17 Houcine A, Delalleau A, Heraud S, Guiraud B, Payre B, Duplan H, et al. How biophysical in vivo testing techniques can be used to characterize full thickness skin equivalents. Skin Res Technol. 2016 Aug;22(3):284-94.

18 Batz S, Wahrlich C, Alawi A, Ulrich M, Lademann J. Differentiation of different nonmelanoma skin cancer types using oct. Skin Pharmacol Physiol. 2018;31(5):238-45.

19 Czekalla C, Schönborn KH, Markworth S, Ulrich M, Göppner D, Gollnick H, et al. Technical parameters of verticalin vivomultiphoton microscopy: A critical evaluation of the flyscanning method. Laser Phys Lett. 2015; 12(8):085602.
20 Fitzpatrick TB. The validity and practicality of sun-reactive skin types I through VI. Arch Dermatol. 1988 Jun;124(6):869-71.

21 Czekalla C, Schönborn KH, Döge N, Jung S, Darvin ME, Lademann J, et al. Body regions have an impact on the collagen/elastin index of the skin measured by non-invasive in vivo vertical two-photon microscopy. Exp Dermatol. 2017 Sep;26(9):822-4.

22 Döge N, Thiel E, Seewald G, Albrecht S, Vogt A, Liebscher J, et al. Wide-field two photon microscopy. Optik\&Photonik. 2015;10(5):39-42.

23 Huang AS, Gonzalez JM Jr, Le PV, Heur M, Tan JC. Sources of structural autofluorescence in the human trabecular meshwork. Invest Ophthalmol Vis Sci. 2013 Jul;54(7):4813-20.

24 Welzel J. Optical coherence tomography in dermatology: a review. Skin Res Technol. $2001 \mathrm{Feb} ; 7(1): 1-9$.

25 Koehler MJ, Hahn S, Preller A, Elsner P, Ziemer M, Bauer A, et al. Morphological skin ageing criteria by multiphoton laser scanning tomography: non-invasive in vivo scoring of the dermal fibre network. Exp Dermatol. 2008 Jun;17(6):519-23.

26 Knott A, Reuschlein K, Lucius R, Stäb F, Wenck H, Gallinat S. Deregulation of versican and elastin binding protein in solar elastosis. Biogerontology. 2009 Apr;10(2):181-90.

27 Czekalla C, Schönborn KH, Döge N, Jung S, Darvin ME, Lademann J, et al. Impact of body site, age, and gender on the collagen/elastin index by noninvasive in vivo vertical twophoton microscopy. Skin Pharmacol Physiol. 2017;30(5):260-7.

28 Rajadhyaksha M, González S, Zavislan JM, Anderson RR, Webb RH. In vivo confocal scanning laser microscopy of human skin II: advances in instrumentation and comparison with histology. J Invest Dermatol. 1999 Sep; 113(3):293-303.

29 Huzaira M, Rius F, Rajadhyaksha M, Anderson RR, González S. Topographic variations in normal skin, as viewed by in vivo reflectance confocal microscopy. J Invest Dermatol. 2001 Jun;116(6):846-52.

30 Lock-Andersen J, Therkildsen P, de Fine Olivarius F, Gniadecka M, Dahlstrøm K, Poulsen $\mathrm{T}$, et al. Epidermal thickness, skin pigmentation and constitutive photosensitivity. Photodermatol Photoimmunol Photomed. 1997 Aug;13(4):153-8. 
31 Fruhstorfer H, Abel U, Garthe CD, Knüttel A. Thickness of the stratum corneum of the volar fingertips. Clin Anat. 2000;13(6):429-33.

32 Therkildsen P, Haedersdal M, Lock-Andersen J, de Fine Olivarius F, Poulsen T, Wulf HC. Epidermal thickness measured by light microscopy: a methodological study. Skin Res Technol. 1998 Nov;4(4):174-9.

33 Gambichler T, Boms S, Stücker M, Moussa G, Kreuter A, Sand M, et al. Acute skin alterations following ultraviolet radiation investigated by optical coherence tomography and histology. Arch Dermatol Res. 2005 Nov;297(5):218-25.
34 Kambayashi H, Yamashita M, Odake Y, Takada K, Funasaka Y, Ichihashi M. Epidermal changes caused by chronic low-dose UV irradiation induce wrinkle formation in hairless mouse. J Dermatol Sci. 2001 Aug;27 Suppl 1:S19-25.

35 Whitton JT, Everall JD. The thickness of the epidermis. Br J Dermatol. 1973 Nov;89(5):467-76.

$36 \mathrm{Wu} \mathrm{S}, \mathrm{Li} \mathrm{H}$, Zhang X, Li Z. Optical features for chronological aging and photoaging skin by optical coherence tomography. Lasers Med Sci. 2013 Feb;28(2):445-50.

37 Tsai CC, Chang CK, Hsu KY, Ho TS, Lin MY, Tjiu JW, et al. Full-depth epidermis tomography using a Mirau-based full-field optical coherence tomography. Biomed Opt Express. 2014 Aug;5(9):3001-10.
38 Hori Y, Yasuno Y, Sakai S, Matsumoto M, Sugawara T, Madjarova V, et al. Automatic characterization and segmentation of human skin using three-dimensional optical coherence tomography. Opt Express. 2006 Mar; 14(5):1862-77.

39 Abignano G, Aydin SZ, Castillo-Gallego C, Liakouli V, Woods D, Meekings A, et al. Virtual skin biopsy by optical coherence tomography: the first quantitative imaging biomarker for scleroderma. Ann Rheum Dis. 2013 Nov;72(11):1845-51 